\title{
A PRESERVAÇÃO DIGITAL NA GESTÃO DO TRIBUNAL DE JUSTIÇA DO ESTADO DO PARÁ: UM ESTUDO DE CASO
}

\author{
EMERSON DE SOUZA PEREIRA* \\ MARIA RAIMUNDA DE SOUSA SAMPAIO**
}

\begin{abstract}
RESUMO
A representatividade do volume informacional digital produzida e custodiada no Tribunal de Justiça do Estado do Pará tem sua relevância nas necessidades de tornar mais acessíveis os documentos adotados na gestão das atividades do TJPA. A pesquisa visa evidenciar os procedimentos de armazenamento e preservação dos documentos digitais na Gestão do TJPA, identificando os formatos e volumes diários da massa informacional produzidas pelos sistemas PJE e SIGADOC, bem como, verificando a existência de política de preservação digital, os formatos adotados para os objetos digitais e os atores informacionais e, por fim, descrevendo as práticas de preservação adotadas por este órgão do Poder Judiciário. Este estudo se baseia em uma pesquisa bibliográfica, em bases de dados, em artigos científicos, em livros e dissertações, disponíveis em bibliotecas físicas e em meio eletrônico. A pesquisa é um estudo de caso com enfoque qualitativo, descritivo, a partir da utilização de um questionário como instrumento de pesquisa, aplicado a três servidores da Secretaria de Informática, caracterizando a amostra. Após análise dos dados, constataram-se algumas carências, tais como: a) embora a política de preservação seja mencionada, não é explícita ou divulgada; b) somente uma estratégia de preservação é adotada; c) não há o envolvimento dos atores informacionais em atividades ligadas à preservação digital; d) não há a participação em rede colaborativa de preservação, entre outras. Porém, um aspecto tecnológico que deve ser mencionado é o fato da utilização de SGBD (Sistema Gerenciador de Banco de dados) e o Data Center institucional, para a guarda dos documentos digitais.
\end{abstract}

PALAVRAS-CHAVE: Preservação digital. Documento digital. Objeto digital. Estratégias de preservação digital.

\footnotetext{
Bacharel em Biblioteconomia pela Faculdade de Biblioteconomia (FABIB/ICSA/UFPA)

Doutoranda em Gestão Empresarial (UAA). Mestre em Ciência da Informação (IBICT/UFRJ). Docente da Faculdade de Biblioteconomia (FABIB/ICSA/UFPA). Bacharel em Biblioteconomia (UFPA)
} 


\title{
DIGITAL PRESERVATION IN THE MANAGEMENT OF THE COURT OF JUSTICE OF THE STATE OF PARÁ: A CASE STUDY
}

\begin{abstract}
The representativeness of the digital information volume produced and guarded at the Court of the State of Pará has its relevance in the needs of making more accessible the documents adopted in the management of TJPA activities. The research aims to highlight the procedures of storage and preservation of digital documents in the TJPA Management, identify the formats and daily volume of information mass produced by the PJE and SIGADOC systems, as well as verify the existence of digital preservation policy; the formats adopted for digital objects; the informational actors and describe the preservation practices adopted by this judiciary body. This study is based on bibliographic research, databases, scientific articles, books and dissertations, available in physical libraries and in electronic media. The research is a case study with a qualitative, descriptive approach, using a questionnaire as a research tool, applied to three servers of the Secretariat of Informatics, characterizing the sample. Subsequently, after analyzing the data, some deficiencies were found, such as, although the preservation policy is mentioned, it is not explicit or disclosed; only one preservation strategy is adopted; There is no involvement of informational actors in activities related to digital preservation; There is no participation in a collaborative preservation network, among others. However, a technological aspect that should be mentioned is the fact that the use of DBMS (Database Management System) and the institutional Data Center to store digital documents.
\end{abstract}

KEYWORDS: Digital preservation. Digital document. Digital object. Preservation strategies.

\section{INTRODUÇÃO}

Os impactos da constante evolução das Tecnologias da Informação e Comunicação (TIC) atingem e beneficiam nossa sociedade de maneira irreversível. As comunicações, as relações sociais e de trabalho, o fazer das rotinas administrativas, entre outras tarefas, evoluem e modificam as organizações. Graças aos avanços tecnológicos, os documentos digitais, semelhantemente a qualquer outro documento em papel, estão suscetíveis a efeitos nocivos, com o passar do tempo. Entre eles, é possível citar a obsolescência tecnológica.

Com o presente trabalho, busca-se o estudo a respeito do tema da preservação digital, bem como, suas práticas no que se refere ao produto informacional digital - documento digital/eletrônico - no domínio do Tribunal de Justiça do Estado do Pará (TJPA). 
Para subsidiar a gestão da preservação digital, no TJPA surgiram o Sistema de Processo Judicial Eletrônico (PJE) e o Sistema Integrado de Gestão Administrativa (SIGADOC). Os sistemas informacionais promovem a produtividade, a otimização dos processos de trabalho e o melhor aproveitamento de recursos humanos e da economia de material, objetivando maior celeridade e qualidade em suas atividades.

Com a utilização destes sistemas, todos os envolvidos em um processo judicial ou rotina administrativa podem interagir de forma eletrônica e segura. Isso porque, a utilização dos seus recursos e funcionalidades exigem a certificação e a assinatura digital de todos os usuários que com eles interagem, além de conferir aos atos realizados o devido valor legal.

A questão problema está inserida na investigação da existência ou não de estratégia de guarda e preservação digital. Em caso de sua existência, quais são adotadas por este órgão do Poder Judiciário? Este estudo tem sua relevância e justificativa na necessidade de mitigar os riscos de perda ou inacessibilidade futura dos documentos digitais deste tribunal. Isso ocorre em virtude da massa informacional digital produzida e custodiada no processo de gestão do TJPA, e a importância que esta possui para suas atividades.

O objetivo geral é evidenciar os procedimentos de guarda e preservação dos documentos digitais na Gestão do TJPA. Os objetivos específicos são: a) identificar os formatos e volumes diários das massas informacionais produzidas pelos sistemas PJE e SIGADOC; b) apresentar os procedimentos práticos de guarda e preservação dos documentos digitais e/ou eletrônicos adotados para gestão do TJPA.

\section{SISTEMAS SIGADOC E PJE}

O Tribunal de Justiça do Estado do Pará, impulsionado pela informatização da justiça, tem implantado inovações tecnológicas. Nesse contexto, surge a utilização de softwares, produtores de informação digital, ou seja, os documentos eletrônicos. Estes sistemas informáticos reproduzem todos os procedimentos de registro, armazenamento e manipulação dos atos judiciais ou administrativos em meio digital. Estas mudanças objetivam a racionalização da prestação jurisdicional, bem como, conferem maior celeridade aos trâmites de ações e rotinas administrativas. 
Segundo Freire e Unger (2008) os sistemas de informação têm sido desenvolvidos para o fluxo de informações relevantes dentro das organizações. Neste sentido, os autores ensinam:

Os sistemas de informação são componentes fundamentais de uma organização social, cuja principal característica é o intenso fluxo informacional, possibilitado, em grande parte, pelos estoques de documentos (em variados suportes) que viabilizam os armazenamentos, a organização e o tráfego da informação, e também pela proliferação da tecnologia da informação e comunicação que embasam e permitem o trânsito das informações. (FREIRE; UNGER, 2008, p. 95).

\subsection{SIGADOC}

O Tribunal de Justiça do Estado do Pará implantou o SIGADOC, impulsionado pelo projeto Processo Administrativo Digital. Este propunha a automação desde o registro até a tramitação de expedientes e processos administrativos no Poder Judiciário do Pará, abolindo integralmente, o uso do papel. Seu objetivo era a eficiência operacional, promovendo a integração e a celeridade nos serviços administrativos.

Este sistema, desenvolvido e utilizado durante anos pela Justiça Federal, na Seção Judiciária do Rio de Janeiro, foi cedido ao TJPA, por meio de convênio de cooperação técnica. Coube, neste contexto, à Secretaria de Informática, adaptá-lo às suas necessidades e ao ambiente computacional.

O SIGADOC é um software, ou seja, um sistema automatizado cuja estrutura permite a manipulação de informações administrativas - expedientes e processos administrativos - com a gerência total do registro, classificação, tramitação, armazenamento e recuperação. Promove o aperfeiçoamento da área administrativa, a otimização dos processos de trabalho e a significativa produtividade e qualidade dos serviços.

$O$ acesso às suas funcionalidades e recursos está condicionado aos usuários possuírem matrícula funcional no TJPA e certificado digital. A necessidade desse certificado ocorrerá quando houver prerrogativas institucionais para assinar, digitalmente, documentos.

No SIGADOC, as informações possuem estreita relação com assuntos administrativos desta instituição, sob variados tipos, tais como, certidão, declaração, memorando, portaria, para citar alguns exemplos. Sua visualização e manipulação é possível apenas quando houver necessidade. 


\section{PJE}

O PJE foi criado pelo Conselho Nacional de Justiça (CNJ), em parceria com outros tribunais e a participação da Ordem dos Advogados do Brasil (OAB), tendo em seu escopo a automação do Judiciário. É uma ferramenta gratuita, disponibilizada a todos os tribunais brasileiros, possibilitando a tramitação e o acompanhamento processual, independentemente do ramo da justiça.

A criação do Processo Judicial Eletrônico (PJE) foi instituída pela Resolução CNJ, n. 185, de 18 de dezembro de 2013, com o objetivo de:

[...] convergir esforços dos tribunais brasileiros para a adoção de uma solução única, gratuita para os próprios tribunais e atenta para requisitos importantes de segurança e de interoperabilidade, racionalizando gastos com elaboração e aquisição de softwares e permitindo o emprego desses valores financeiros e de pessoal em atividades mais dirigidas à finalidade do Judiciário: resolver os conflitos (CONSELHO NACIONAL DE JUSTIÇA, 2013).

O PJE começou a ser utilizado, oficialmente, no Pará, a partir de outubro de 2014. Atualmente, é usado nos Juizados Especiais Cíveis, no CEJUSC, na Turma Recursal e em algumas Varas Cíveis.

\section{PRESERVAÇÃO DIGITAL}

A essência dos documentos digitais permite ampla produção e uso e disseminação de informações. Isso porque, no cenário tecnológico e cultural utiliza-se cada vez mais conteúdos e documentos eletrônicos.

Esses documentos digitais, estão sujeitos a diversos efeitos nocivos com o passar dos anos. Muitos possuem valores jurídicos legais, fiscalizadores e de controle presumíveis de serem considerados como documentos históricos, semelhantemente, a qualquer documento oficial em suporte físico (de papel) Entre eles, podemos citar a obsolescência tecnológica.

Preservação digital, conforme o dicionário de Biblioteconomia e Arquivologia, é definida como o "processo de armazenamento, em condições adequadas para o uso de documentos ou objetos produzidos em formato digital" (CUNHA; CAVALCANTI, 2008, p. 290). Para Margaret Hedstrom (1996 apud ARELLANO, 2004, p. 17) é "[...] o planejamento, alocação de recursos e aplicação de métodos e tecnologias para assegurar que a informação digital de valor continuo permaneça acessível e utilizável". 
Neste sentido, podemos inferir que se constituem na adoção de ações e tecnologias que garantam o acesso a materiais digitais, transpondo falhas da mídia e/ou mudanças tecnológicas.

Nesse contexto, Baggio e Flores (2012) evidenciam que:

Como respostas a este desafio, surgem estratégias de preservação digital que procuram incorporar todos os aspectos relacionados a esta problemática: custos, legislação, gestão, acesso, políticas e critérios. As estratégias reúnem soluções parciais ante um problema complexo, estando envolvidos, entre outros itens, a migração, emulação, arqueologia digital, criptografia, metadados, tecnologias livres, ou abertas como XML, HTML, Dublin Core (BAGGIO; FLORES, 2012, p. 59).

A problemática da preservação digital é reconhecida internacionalmente como uma questão para a memória mundial, tendo a UNESCO publicado, em 2012, a Declaração de Vancouver (UNESCO, 2012), Isto culminou como resultado do encontro de vários pesquisadores mundiais na busca de um consenso sobre o fato. Ademais, no caso das instituições públicas nacionais, estas estão submetidas à Lei de Acesso à Informação, tornando implícita a implementação de uma política de preservação digital. (BRASIL, 2011a)

A adoção de tecnologia, como maneira de aperfeiçoamento das estratégias de preservação digital é empregada por instituições de várias partes do mundo, em virtude dos benefícios que proporciona. Ademais, pesquisadores, em nível mundial, como uma força-tarefa, buscam, com o estudo dessa temática, desenvolver modelos de uma infraestrutura para a preservação, a longo prazo, da informação em formato digital, garantindo sua longevidade e acesso perenes.

Ferreira (2006) ensina-nos que as estratégias de preservação digital são caracterizadas por procedimentos que visam garantir o acesso ao documento digital. Além disso, almejam ampliar sua em todo o ciclo, desde o ato de sua criação até sua destinação final.

Neste sentido, diversificadas estratégias são mencionadas como possíveis soluções. Entretanto, conforme a literatura pesquisada e entre seus autores, há o consenso de que nenhuma delas resolve a problemática da preservação, principalmente se for implantada isoladamente. 


\section{PROCEDIMENTOS METODOLÓGICOS}

A metodologia utilizada neste trabalho baseia-se em uma pesquisa bibliográfica, em bases de dados, artigos científicos, livros e dissertações. Estas estão disponíveis em bibliotecas físicas e em meio eletrônico, buscando o embasamento teórico sobre o tema preservação digital e temas correlatos.

Esta pesquisa é um estudo de caso e está inserida em uma abordagem qualitativa. O locus de observação é o Tribunal de Justiça do Estado do Pará e a amostra será da Secretaria de Informática, tendo como participantes três servidores integrantes desta: um assessor e dois analistas de sistemas. Estes foram designados para serem os respondentes às questões do instrumento de pesquisa, tipificando a totalidade da amostra.

O instrumento utilizado será a aplicação de um questionário com perguntas abertas e fechadas pré-estabelecidas, relacionadas à preservação digital e aos documentos digitais, gerados a partir dos sistemas PJE e SIGADOC. Posteriormente à aplicação do questionário e, com base nos dados informados, serão demonstrados, com a utilização de quadros, os resultantes desta pesquisa. Estes apresentarão o que foi apurado através da opinião dos servidores.

O referencial teórico, por sua vez, está direcionado através de pesquisa bibliográfica, em bases de dados, preferencialmente, em periódicos nacionais indexados pela Base de Dados Referenciais de Artigos de Periódicos em Ciência da Informação (BRAPCI). O recorte temporal que corresponde aos artigos sobre preservação digital é de 2000 a 2017. A base dispõe de um total de 57 periódicos nacionais de Ciência da Informação, que são referenciados e resumidos.

$\mathrm{Na}$ pesquisa realizada na $\mathrm{BRAPCl}$, foram utilizadas as palavras-chave preservação digital; documento eletrônico; estratégias de preservação digital; política de preservação digital; preservação de documentos digitais e documento digital. Foram recuperados um total de 187 artigos, dos quais se usou 20 trabalhos, que geraram 21 autores.

\section{ANÁLISE DOS DADOS}

A finalidade da análise foi a obtenção de resultados com o intuito de apresentar o panorama da guarda e preservação digital. Estes foram relacionados aos documentos eletrônicos, produzidos 
no âmbito do TJPA, pelos sistemas SIGADOC e PJE. O questionário, instrumento de pesquisa, foi aplicado por e-mail.

Antes do início das perguntas do questionário, foi solicitada a identificação e a função do respondente. Entretanto, estas serão mantidas em sigilo, pois, identificaremos os 3 conforme a necessidade de utilização de respostas. Os dados foram recebidos via e-mail, em: 22 fev. 2018.

De acordo com as respostas obtidas, com base no instrumento, temos:

A primeira pergunta visava constatar, no âmbito institucional e organizacional, sobre a existência de um instrumento oficial, instituindo as ações de preservação digital. E, em caso de resposta afirmativa, foi solicitada sua anexação para consulta pública. Observa-se, por intermédio do Quadro 1, sobre sua existência:

Quadro 1 - Sobre a existência de uma política de preservação digital

\begin{tabular}{|c|c|c|c|}
\hline \multirow{2}{*}{ Opção Resposta } & \multicolumn{3}{|c|}{ Respondentes } \\
\cline { 2 - 4 } & ASS 1 & ASS 2 & ASS 3 \\
\hline Sim & $X$ & $X$ & $X$ \\
\hline Não & - & - & - \\
\hline
\end{tabular}

FONTE: autoria própria, 2018

De acordo com os respondentes, obtivemos o resultado afirmativo, caracterizando a totalidade, informando que este órgão judicial possui política de preservação. Porém, a respeito do documento solicitado não houve posicionamento se poderia ser disponibilizado. Apesar disso, tivemos a informação de que a preservação digital se dá nos metadados e conteúdos dos documentos nato-digitais, tendo em vista, a utilização e implementação das ferramentas informáticas (PJE) e (SIGADOC), exigindo que os documentos surgidos a partir de sua implementação sejam digitais na sua totalidade.

Nesse contexto, é imprescindível que exista um instrumento oficial com diretrizes definidas, que servirá de guia e orientação para ações de preservação digital. Os autores Silva Júnior e Mota (2012) salientam acerca da importância da implantação de uma política de preservação digital que:

[...] serve como orientação legal para a gestão da preservação e para o acesso permanente aos objetos digitais produzidos, selecionados e armazenados por suas respectivas empresas ou instituições, e visa à superação da obsolescência tecnológica tanto dos objetos como dos seus próprios suportes. Uma política dessa natureza é elaborada com base em resoluções, normas, atos administrativos, leis, modelos 
e padrões. Pode ser analisada sob o aspecto organizacional, legal e técnico. Além disso, pode estar inserida em um programa mais amplo de preservação, conforme caracterização atribuída pela Carta para a Preservação do Patrimônio Digital elaborada pela Biblioteca Nacional da Austrália e publicada pela Unesco, em 2003. A carta serve de base conceitual para as principais iniciativas e projetos internacionais em preservação digital. (SILVA JÚNIOR; MOTA, 2012, p. 51).

Podemos inferir que a política de preservação digital de uma instituição deve ser amparada por normas, leis, padrões nacionais e internacionais, com vistas a assegurar os direitos legais e a autenticidade destes objetos digitais.

A segunda pergunta apresentava múltiplas escolhas, tratando de aspectos técnicos relacionados à preservação da massa informacional eletrônica. O Quadro 2 mostra que poderiam ser escolhidas mais de uma das alternativas, em que se pretendia descobrir as estratégias operacionais em que eram empregadas isoladas ou paralelamente.

Quadro 2 - Estratégia de preservação digital utilizada pelo TJPA

\begin{tabular}{|c|c|c|c|c|c|c|c|c|}
\hline \multirow[b]{2}{*}{ 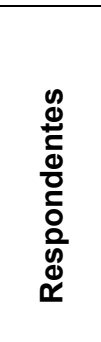 } & \multicolumn{8}{|c|}{ Estratégia Utilizada } \\
\hline & 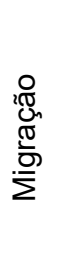 & 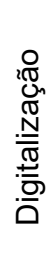 & 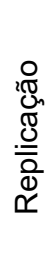 & 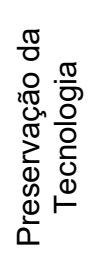 & 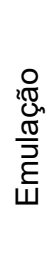 & 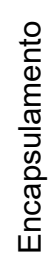 & $\begin{array}{l}0 \\
\frac{0}{0} \\
\frac{\pi}{0} \\
\frac{\pi}{\pi} \\
\frac{\pi}{0} \\
\sum\end{array}$ & $\begin{array}{l}\stackrel{\sqrt[\pi]{0}}{*} \\
0 \\
0\end{array}$ \\
\hline ASS 1 & $\mathrm{X}$ & - & - & - & - & . & . & - \\
\hline ASS 2 & $x$ & - & - & - & - & . & 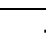 & - \\
\hline ASS 3 & $x$ & - & - & - & - & 7 & 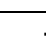 & - \\
\hline
\end{tabular}

FONTE: autoria própria, 2018

Obtivemos o resultado afirmativo para a opção da estratégia de migração como única empregada. Esta ocorre em nível de software, quando há necessidade da transferência dos documentos digitais para versões sucessoras, motivada pela evolução de geração ou substituição de ferramentas que manipulam os documentos. Em síntese, migração é a transferência periódica de materiais digitais, de uma configuração de plataforma para outra ou de uma geração de tecnologia computacional para a sua sucessora. 
Além disso, sobre esta estratégia e a respeito da adição de metadados e detalhamento da alteração ocorrida, Rocha (2016) nos diz que:

Toda a transferência de um suporte antigo ou obsoleto para algo mais recente é necessário que seja documentado em detalhes com suas características, sua história e todas alterações sofridas por ele ao longo do tempo, de modo padrão para que mesmo que a equipe se modifique, ao longo do tempo, nada seja perdido - característica básica e principal dos metadados. (ROCHA, 2016, p. 42).

$\mathrm{Na}$ terceira pergunta, intencionávamos perceber a participação do TJPA em alguma iniciativa de preservação digital colaborativa ou em rede distribuída, instituída pelo CNJ ou não, ensejando a preservação de acervos informacionais autênticos e com certificação de instituições reconhecidas. O Quadro 3, a seguir, evidenciou a não participação.

Quadro 3 - Sobre a participação do TJPA em alguma iniciativa colaborativa de preservação.

\begin{tabular}{|c|c|c|c|}
\hline \multirow{2}{*}{ Iniciativa Colaborativa } & \multicolumn{3}{|c|}{ Respondentes } \\
\cline { 2 - 4 } & ASS 1 & ASS 2 & ASS 3 \\
\hline Instituída pelo CNJ & - & - & - \\
\hline LOCKSS / Rede Cariniana & - & - & - \\
\hline Outra (especificar) & - & - & - \\
\hline Nenhuma & $\mathrm{X}$ & $\mathrm{X}$ & $\mathrm{X}$ \\
\hline
\end{tabular}

FONTE: autoria própria, 2018

Os respondentes não especificaram iniciativas colaborativas de preservação digital. Entretanto, se reportaram ao processo de digitalização referente aos documentos analógicos, oriundos da instância do $1^{\circ} \mathrm{Grau}$ de Justiça. Esses documentos gerados nessa instância necessitaram ser digitalizados.

Corroborando a necessidade de participação nestas iniciativas de preservação digital, conforme literatura pesquisada, Márdero Arellano (2012), nos ensina, dizendo:

Entre os métodos estruturais atuais encontra-se o modelo de preservação em redes colaborativas, que aponta para a necessidade de contar com especialistas conhecedores de sistemas de produção de materiais autênticos e de instituições que validem seus objetos digitais. Dada a vulnerabilidade desses objetos, as organizações precisam incorporar serviços de preservação digital para seus conteúdos ou correr o risco de perder esses acervos irreparavelmente. (MÁRDERO ARELLANO, 2012, p. 84). 
$\mathrm{Na}$ quarta pergunta, tencionava-se revelar, no campo organizacional da instituição, se membros da Secretaria de Informática, estariam envolvidos nas atividades de preservação digital. Isso porque, há a necessidade da interação multiprofissional em um programa dessa envergadura e complexidade e, assim, a equipe de profissionais esteja imbuída e tenha adquirido habilidades e conhecimentos teórico-práticos para o desenvolvimento de uma função especializada. Em seguida, o Quadro 4 demonstra que nenhum membro está envolvido.

Quadro 4 - Quantidade de membros da Secretaria de Informática, envolvidos na preservação digital.

\begin{tabular}{|c|c|c|c|}
\hline Quantidade de Membros & \multicolumn{3}{|c|}{ Respondentes } \\
\cline { 2 - 4 } Envolvidos & ASS 1 & ASS 2 & ASS 3 \\
\hline Um membro & - & - & - \\
\hline Dois membros & - & - & - \\
\hline Três membros & - & - & - \\
\hline Nenhum & X & X & X \\
\hline
\end{tabular}

FONTE: autoria própria, 2018

Os respondentes informaram que nenhum membro estaria envolvido nesta atividade. Dessa forma, percebemos a sinalização da carência do envolvimento nas atividades de preservação digital. Tendo em vista que é imprescindível o envolvimento dos mais variados profissionais, desde o planejamento até a execução das atividades pertinentes à preservação digital dessa massa informacional.

$\mathrm{Na}$ quinta pergunta, pretendíamos demonstrar se havia a formação acadêmico-multidisciplinar dos membros envolvidos, devido à complexidade da gestão e à consecução de um programa preservacionista. Logo após, o Quadro 5 elenca as opções que poderiam demonstrar a formação heterógena dos envolvidos. Os respondentes informaram não dispor desta informação.

Quadro 5 - Formação acadêmica dos membros envolvidos na preservação digital. Dados recebidos via e-mail em: 22 fev. 2018.

\begin{tabular}{|l|c|c|c|}
\hline \multirow{2}{*}{$\begin{array}{c}\text { Formação Acadêmica } \\
\text { dos Membros Envolvidos }\end{array}$} & \multicolumn{3}{c|}{ Respondentes } \\
\cline { 2 - 4 } & ASS 1 & ASS 2 & ASS 3 \\
\hline Ciência da Informação & - & - & - \\
\hline Informática & - & - & - \\
\hline Sistemas de Informação & - & - & - \\
\hline Direito & - & - & - \\
\hline Administração & - & - & - \\
\hline Engenharia & - & - & - \\
\hline Outra & - & - & - \\
\hline
\end{tabular}

FONTE: autoria própria, 2018 
Neste contexto, Grácio (2012, p. 86), adverte que "para tratar problemas de natureza tão distintas, não existe atualmente um profissional que possua formação tão ampla e variada". Diante disto, este autor ratifica sobre a necessidade da constituição de uma:

Equipe multidisciplinar, com profissionais especialistas em várias áreas para a gestão dos processos, das atividades e das pessoas envolvidas na preservação digital. Além de bibliotecários, arquivistas e profissionais da Ciência da Informação, são indispensáveis profissionais das áreas de Informática, Sistemas de Informação, Direito, Administração, Engenharia, [...] administrativos [...] e outros que a instituição julgar necessários. (GRÁCIO, 2012, p. 86)

Desta feita, cada membro envolvido vislumbrará a informação digital - o documento eletrônico - de maneira geral e também, especifica, em relação a sua área de conhecimento ou atuação.

$\mathrm{Na}$ sexta pergunta, objetivava-se mostrar $\mathrm{O}$ aspecto organizacional relacionado ao envolvimento de pessoas nas atividades de preservação digital, bem como as suas descrições reflexivas, técnicas ou decisórias. Obtivemos a resposta de que não dispunham dessa informação. Conforme o Quadro 6, não foi possível diagnosticar nenhuma das atividades.

Quadro 6 - Atividades dos membros envolvidos na preservação digital

\begin{tabular}{|l|c|c|c|}
\hline \multicolumn{1}{|c|}{$\begin{array}{l}\text { Descrição das Atividades } \\
\text { dos Membros Envolvidos }\end{array}$} & \multicolumn{3}{|c|}{ Respondentes } \\
\cline { 2 - 4 } & ASS 1 & ASS 2 & ASS 3 \\
\hline Replicação de conteúdos e backup & - & - & - \\
\hline Participação em reuniões & - & - & - \\
\hline $\begin{array}{l}\text { Participação em reuniões técnicas para } \\
\text { autorização de medidas preservacionistas }\end{array}$ & - & - & - \\
\hline $\begin{array}{l}\text { Participação em reuniões para a escolha de } \\
\text { estratégias de preservação }\end{array}$ & - & - & - \\
\hline
\end{tabular}

FONTE: autoria própria, 2018

As atividades técnicas compreendem a operação dessas atividades, as reflexivas e decisórias, seriam pertinentes à concepção da política de preservação digital, à escolha do material digital a ser preservado, bem como, aos seus padrões e formatos, e também, às estratégias a serem adotadas.

No ensino de Grácio (2012):

Após inserir em seus objetivos a preservação digital e definir uma equipe multidisciplinar para promover a gestão dos objetos digitais a serem preservados, a [...] [instituição] deve definir o papel de cada um dos envolvidos, com o objetivo de identificar e apontar responsabilidades (GRÁCIO, 2012, p. 89). 
Ou seja, este autor, destaca a necessidade de definição das responsabilidades dos envolvidos na preservação digital. E, ainda, adverte, "[...] a preservação digital é responsabilidade do criador do objeto digital, da própria instituição e de todas as pessoas envolvidas nos processos" (GRÁCIO, 2012, p. 89).

A sétima pergunta propunha-se a identificar o aspecto técnico relacionado ao formato ou padrão adotado para o produto informacional, ou seja, o documento eletrônico, produzido pelos sistemas PJE e SIGADOC. Nesta, os respondentes mencionaram e elencaram as espécies e tipos documentais, tais como: a petição inicial, a sentença, o memorando, o requerimento, entre outros, todos de gênero textual. O Quadro 7, a seguir, elenca três formatos, entretanto, nenhum foi mencionado.

Quadro 7 - Formato adotado para os documentos eletrônicos gerados pelo PJE e SIGADOC

\begin{tabular}{|l|c|c|c|}
\hline Formato Adotado Para Os Documentos & \multicolumn{3}{|c|}{ Respondentes } \\
\cline { 2 - 4 } Digitais & ASS 1 & ASS 2 & ASS 3 \\
\hline Doc-Document & - & - & - \\
\hline Pdf - Portable Data Format & - & - & - \\
\hline Html - Hypertext Markup Language & - & - & - \\
\hline
\end{tabular}

FONTE: autoria própria, 2018

Entretanto, detendo-nos à questão dos formatos, o TJPA regulamenta e disciplina este aspecto por meio de atos jurídico-normativos, delineando o uso dos sistemas informáticos $\mathrm{e}$ instituindo o formato padrão para o produto informacional, o documento eletrônico. Isso porque, o art. 16 da Portaria Conjunta $n^{\circ} 001$ - GP/VP, de 2018, em relação ao PJE, assim disciplina:

O sistema Pje receberá arquivos nos formatos definidos pelo $\mathrm{CNJ}$, observando os seguintes parâmetros:

I - texto: formato PDF (Portable Document Format) até 5 (cinco) Mb (TRIBUNAL DE JUSTIÇA DO ESTADO DO PARÁ, 2018, p. 16).

$\mathrm{E}$, no que tange ao SIGADOC, a Portaria $\mathrm{n}^{\circ} 2766$, de 2014, no seu art. $3^{\circ}$, inciso I, traz a seguinte recomendação:

$\S 1^{\circ} \mathrm{O}$ formato/extensão dos documentos produzidos em meio eletrônico para inserção no SigaDoc será o PDF - portable document format (TRIBUNAL DE JUSTIÇA DO ESTADO DO PARÁ, 2014, p. 9).

A adoção de padrões e formatos internacionais é caracterizada como uma ação imprescindível para a preservação 
digital "por possibilitar a troca de experiências e informações entre instituições, além de auxiliar na padronização [...] dos objetos digitais a serem preservados" (GRÁCIO, 2012, p. 113).

$\mathrm{Na}$ oitava pergunta, desejava-se exibir a quantidade média-diária de documentos originados nos sistemas, tendo em vista, a crescente demanda por prestação jurídica. Além disso, levou-se em consideração a necessidade de armazenagem/salvaguarda destes objetos digitais.

De acordo com as respostas, alcançamos o resultado demonstrado no Quadro 8:

Quadro 8 - A quantidade de documentos digitais produzidos nos sistemas PJE e SIGADOC

\begin{tabular}{|c|c|}
\hline Sistema Produtor e Instância & $\begin{array}{c}\text { Quantidade Média Produzida } \\
\text { Diária e Individualmente }\end{array}$ \\
\hline PJE 1 Grau & 7.825 \\
\hline PJE 2 Grau & 825 \\
\hline SIGADOC & 453 \\
\hline Média Geral Produzida Diariamente & 9.103 \\
\hline
\end{tabular}

FONTE: autoria própria, 2018

Diante do contexto local apresentado, podemos concluir, com estes dados, um cenário alarmante e preocupante, tendo em vista $o$ crescimento na demanda por prestação jurisdicional mais rápida.

A nona pergunta dispunha-se mostrar os atores informacionais, produtores e consumidores das informações digitais, configurados no contexto da preservação digital, enquanto os elementos básicos. Estes permitem, de forma direta ou indireta, a concretização das ações preservacionistas.

Os dados do Quadro 9 demonstraram que existe a formação heterogênea com magistrados, servidores, advogados, entre outros. Estes atores desempenham atividades do meio ao fim. Em relação ao público externo, restou caracterizada a possibilidade de consulta aos documentos digitais.

Quadro 9 - Atores informacionais e suas interações com os documentos digitais produzidos nos sistemas PJE e SIGADOC

\begin{tabular}{|c|c|c|}
\hline Sistema Produtor & Ator Informacional & Nível de Interação \\
\hline \multirow{4}{*}{ Pje } & $\begin{array}{c}\text { Desembargadores, } \\
\text { Magistrados, Servidores, } \\
\end{array}$ & $\begin{array}{c}\text { Advogados, } \\
\text { Procuradores, } \\
\text { Defensores. }\end{array}$ \\
& $\begin{array}{c}\text { Geração de } \\
\text { documentos }\end{array}$ \\
\cline { 2 - 3 } & Público externo & Consulta pública \\
\hline
\end{tabular}


Continuação

\begin{tabular}{|c|c|c|}
\hline Sistema Produtor & Ator Informacional & Nível de Interação \\
\hline \multirow{2}{*}{ SIGADOC } & $\begin{array}{c}\text { Usuários cadastrados no } \\
\text { sistema (Magistrados, } \\
\text { servidores e } \\
\text { estagiários). }\end{array}$ & $\begin{array}{c}\text { Geração de } \\
\text { documentos }\end{array}$ \\
\cline { 2 - 3 } & Público externo & Consulta pública \\
\hline
\end{tabular}

FONTE: autoria própria, 2018

Entretanto, para Grácio (2012), além da divulgação, conscientização e comprometimento dos atores informacionais, a política de preservação digital deverá estar inserida em um contexto mais amplo, uma vez que, tal implementação irá impactar na cultura organizacional. Isto ocorrerá em aspectos como valores, crenças, rituais, mitos, normas, processos de comunicação e o comportamento organizacional.

As perguntas 10,11, 12 e 13 verificam aspectos técnicos importantes, intrinsecamente ligados à preservação digital dos documentos eletrônicos. As respostas indicaram a utilização de banco de dados; critérios norteadores para o tempo de guarda e a existência de repositório institucional.

Quadro 10 - Sobre método, período e/ou critério de guarda e existência de repositório digital

\begin{tabular}{|c|c|c|c|}
\hline $\begin{array}{c}\text { Sistema } \\
\text { Produtor }\end{array}$ & $\begin{array}{c}\text { Método de } \\
\text { Guarda dos } \\
\text { Documentos } \\
\text { Digitais }\end{array}$ & $\begin{array}{c}\text { Período e Critério } \\
\text { de Armazenamento }\end{array}$ & Repositório \\
\hline Pje & SGBD & $\begin{array}{c}\text { Não existe PCTT. } \\
\text { Até o momento, } \\
\text { nada é descartado. }\end{array}$ & $\begin{array}{c}\text { Institucional - } \\
\text { Data center }\end{array}$ \\
\hline SIGADOC & SGBD & $\begin{array}{c}\text { O descarte é } \\
\text { definido pelo PCTT. } \\
\text { Entretanto, pela } \\
\text { disponibilidade de } \\
\text { armazenamento, } \\
\text { não há descarte. }\end{array}$ & $\begin{array}{c}\text { Institucional - } \\
\text { Data center }\end{array}$ \\
\hline
\end{tabular}

FONTE: autoria própria, 2018

Os aspectos técnicos abordados são demonstrados no Quadro 10. Os critérios de seleção daquilo que deve ser preservado e/ou descartado, bem como, da utilização de repositórios digitais são compostos pelos métodos utilizados para armazenar, determinar o tempo de permanência ou guarda destes objetos eletrônicos. 
As respostas revelaram, em relação à infraestrutura tecnológica, o uso de um Sistema Gerenciador de Banco de Dados (SGBD). O SGBD, no ensino de Grácio (2012, p. 136), afirma que: "possibilita que um grande volume de informação seja armazenado e preservado em espaços físicos pequenos, mas com grande capacidade de armazenamento".

Outro aspecto revelado está relacionado ao ambiente que acomoda a infraestrutura de hardware do porte de uma instituição como o TJPA, ou seja, um Data Center:

que pode ser definido como um espaço projetado com segurança, dentro de uma organização, onde estão instalados os equipamentos de rede e de processamento e armazenamento de dados (GRÁCIO, 2012, p. 136).

Estes dois primeiros aspectos representam um quadro favorável para assegurar o acesso, a longo prazo, e o uso destes objetos digitais. Outro aspecto a ser considerado é a definição de critérios que justifiquem o que deve ser preservado e por quanto tempo deverá sê-lo:

O tempo que um objeto digital precisa ser preservado deve estar de acordo com as especificações legais, estipuladas em lei, normas e portarias, bem como, com sua frequência de uso para o caso de objetos que não sofrem restrições legais. (GRÁClO, 2012, p. 112).

Neste sentido, e de acordo com os respondentes, obtivemos a sinalização de uso do Plano de Classificação e Tabela de Temporalidade (PCTT). Estes instrumentos foram utilizados para sistematizar e hierarquizar o assunto tratado nos documentos produzidos ou recebidos por determinado órgão, na consecução de suas atividades. Objetiva a uniformidade no tratamento da documentação, agiliza a recuperação da informação, bem como, serve de orientação para a elaboração da Tabela de Temporalidade.

Fica evidenciado que os documentos digitais, gerados pelo PJE, não foram contemplados, até o momento, com o descarte, em virtude da não existência de PCTT para estes. E, os documentos produzidos pelo SIGADOC, apesar de possuírem o PCTT, não passaram pelo processo de descarte, em razão da disponibilidade de espaço de armazenamento.

Este panorama traz à luz do debate questões intimamente ligadas à preservação, uso e acesso dos objetos digitais. Primeiramente, refere-se à preservação de tudo. Em segundo lugar, 
relaciona-se à necessidade de se manter documentos eletrônicos sem interesse administrativo, jurídico ou histórico.

Neste sentido, ao nos apropriarmos do estudo de Moreira (2015) sobre a temática da avaliação e da destinação dos autos digitais, este autor ressalta que:

Mesmo com temporalidades definidas a partir de estudos sobre prazos prescricionais e precaucionais, os autos acabam permanecendo indefinidamente [...] [nos sistemas]. Isso faz com que o Pje [...] [e o SIGADOC, funcionem] como um grande depósito de ações judiciais [e documentos administrativos], o que implica na necessidade de constante ampliação da capacidade dos bancos de dados. (MOREIRA, 2015, p. 61, grifo nosso).

A décima quarta pergunta era de caráter subjetivo, possibilitando acrescentar algum comentário sobre a preservação digital desenvolvida no TJPA. Entretanto, não houve nenhum comentário dos servidores participantes.

\section{CONSIDERAÇÕES FINAIS}

Este trabalho demonstrou aspectos sobre a preservação dos documentos digitais. Além disso, descreveu e apresentou exemplos de estratégias que têm sido empregadas no contexto da preservação dos documentos digitais. Para sua consecução, foi realizado um estudo de conceitos relativos ao documento digital e objeto digital, bem como, sobre os níveis de abstração deste último, tendo em vista que as ações de preservação serão realizadas sobre ele.

Este estudo não esgota a análise sobre o referido tema. Alguns aspectos ainda estão em construção conceitual, e também, o surgimento constante de novos estudos e ações preservacionistas, na busca de soluções sustentáveis e eficazes para a resolução da problemática dicotômica preservação digital-obsolescência.

$\mathrm{Na}$ pesquisa realizada, constatou-se que a política de preservação digital, embora com existência sinalizada, não ocorre explicitamente, nem é divulgada publicamente. Estes aspectos organizacionais são imprescindíveis, devendo ser incentivados, amplamente, proporcionando mudanças na cultura organizacional. Importa ressaltar que o compromisso com a preservação dos documentos digitais deve atingir a todos os atores informacionais. Assim, todos os servidores desta instituição e usuários dos sistemas PJE e SIGADOC - produtores de informação digital -, que contribuem direta ou indiretamente na obtenção dos objetivos preservacionistas precisam cuidar destes dados. 
Foram constatadas algumas carências, relacionadas a alguns aspectos de um programa preservacionista. Somente uma estratégia foi mencionada, a migração. No contexto da preservação, é necessária a adoção de táticas paralelas, que contemplem os três níveis estruturais de um objeto digital, ou seja, o documento digital.

Outro aspecto que suscita cuidados está relacionado ao binômio demanda-armazenamento. Esta instituição conta com o suporte de boa estrutura tecnológica, através da utilização de SGBD e um Data center, o que significa a possibilidade de armazenamento de grande volume informacional. Em contrapartida, a busca por prestação jurídica mais célere, e, consequentemente, o ingresso de novos processos e atos administrativos eletronicamente pode ocasionar o robustecimento e inchaço deste repositório institucional. Neste contexto, é recomendável evitar a guarda por tempo indefinido de objetos digitais desnecessários às atividades desta instituição.

Conclui-se que um programa preservacionista, dada a amplitude e complexidade para sua execução vários aspectos, deve ser considerado, desde a concepção da política de preservação, os profissionais envolvidos, às estratégias que serão empregadas. Além disso, a política de preservação precisa ser concebida por uma equipe multidisciplinar e divulgada amplamente, como forma de despertar o comprometimento de todos os atores informacionais, envolvidos no processo de criação, preservação e uso da informação digital.

Aliado a isto, a adoção de padrões internacionais, formatos abertos e a aplicação de estratégias paralelas e adequadas de preservação digital de documentos eletrônicos. Esses aspectos contribuem para assegurar a preservação, o armazenamento, o acesso e o uso destes objetos digitais, pertencentes ao acervo informacional do Poder Judiciário do Estado, pelo tempo que for necessário

\section{REFERÊNCIAS}

ARELLANO, M. N. M. R. Preservação de documentos digitais. Ciência da Informação, v. 33, n. 2, p. 15-27, 2004. Disponível em: http://www.brapci. inf.br/v/a/1146. Acesso em: 26 mar. 2018.

ARQUIVO NACIONAL. Glossário de documentos arquivísticos digitais. 6. Versão. Rio de Janeiro: 2014. 
BAGGIO, C. C.; FLORES, D. Estratégias, critérios e políticas para preservação de documentos digitais em arquivos. Ciência da Informação (Online), v. 41, p. 58-71, 2012. Disponível em: http://revista.ibict.br/ciinf/ article/viewFile/1336/1515. Acesso em: 29 set. 2017.

BOERES, S. A. A.; ARELlANO, M. A. M. Políticas e estratégias de preservação de documentos. In: ENCONTRO DE CIENCIA DA INFORMAÇÃO - CINFORM, 6, 2005, Salvador. Anais eletrônicos [...]. Salvador: UFBA, 2005. Disponível em: http://www.cinformanteriores.ufba.br/ vi_anais/docs/SoniaMiguelPreservacaoDigital.pdf. Acesso em: 29 set. 2017.

BRASIL. Decreto $\mathbf{n}^{\circ} \mathbf{8 . 5 3 9}$, de 8 de outubro de 2015. Dispõe sobre o uso do meio eletrônico para a realização do processo administrativo no âmbito dos órgãos e das entidades da administração pública federal direta, autárquica e fundacional. Lex: Legislação federal e marginalia. Poder Executivo. Brasília, DF, 9 out. 2015, seção 1, p. 2.

BRASIL. Lei $n^{\circ} 12.527$ de 18 de novembro de 2011. Regula o acesso a informações previsto no inciso XXXIII do art. $5^{\circ}$, no inciso II do $\S 3^{\circ}$ do art. 37 e no $\S 2^{\circ}$ do art. 216 da Constituição Federal; altera a Lei no 8.112, de 11 de dezembro de 1990; revoga a Lei no 11.111, de 5 de maio de 2005, e dispositivos da Lei $\mathrm{n}^{\circ}$ 8.159, de 8 de janeiro de 1991; e dá outras providências. Diário Oficial da União, Brasília, DF, 18 nov. 2011a.

CONSELHO NACIONAL DE JUSTIÇA (Brasil) (CNJ). Resolução $\mathbf{n}^{\circ} \mathbf{1 8 5}$, de 18 de dezembro de 2013. Institui o Sistema Processo Judicial Eletrônico PJe como sistema de processamento de informações e prática de atos processuais e estabelece os parâmetros para sua implementação e funcionamento. Disponível em: http://www.cnj.jus.br/busca-atos-adm? documento=2492. Acesso em: 29 set. 2017.

CUNHA, Murilo Bastos; CAVALCANTI, Cordélia. Dicionário especializado de biblioteconomia e arquivologia. Brasília: Briquet de Lemos, 2008.

FERREIRA, Miguel. Introdução à preservação digital: conceitos, estratégias e actuais consensos. In: Guimarães, Escola de Engenharia da Universidade do Minho, 2006. Disponível em: http://hdl.handle.net/1822/ 5820. Acesso em: 10 nov. 2017.

FREIRE, Isa Maria; UNGER, Roberto José Gervásio. Regimes de Informação na Sociedade da Informação: uma contribuição para a Gestão da Informação. Revista Digital de Biblioteconomia e Ciência da Informação, Campinas, v. 2, n. 2, p. 87 114, jan./jun. 2008. Disponível em: http://www.sbu.unicamp.br/seer/ojs/index.php/rbci/article/view/384. Acesso em: 10 nov. 2017.

GRÁCIO, J. C. A. Preservação Digital na gestão da informação: um modelo processual para as instituições de ensino superior. São Paulo: Cultura Acadêmica, 2012.

INNARELLI, H. C. Preservação digital e seus dez mandamentos. In: Arquivística: Temas Contemporâneos. 3 ed. Distrito Federal: Senac, 2009. p. 21-75. 
JUNQUEIRA, Gabriel Luiz Herscovici. Arbitragem brasileira na era da informática: um estudo das principais questões processuais. 2014. Dissertação (Mestrado em Direito Processual) - Faculdade de Direito, Universidade de São Paulo, São Paulo, 2014. Disponível em: http://www.teses.usp.br/teses/disponiveis/2/2137/tde-11022015-144147/ptbr.php. Acesso em: 09 out. 2017.

ROCHA, Vânia Melo da. Benefícios e desafios da preservação digital: uma análise para a gestão de um repositório confiável. 2016. 82f. Dissertação - (Programa de Pós-Graduação em Biblioteconomia) - Mestrado Profissional em Biblioteconomia. Universidade Federal do Estado do Rio de Janeiro - UNIRIO. Rio de Janeiro, 2016. Disponível em: http://www.unirio.br/ ppgb/arquivo/vania-melo-da-rocha. Acesso em: 25 set. 2017.

MARCACINI, Augusto Tavares Rosa. Direito e Informática: uma abordagem jurídica sobre a criptografia. Editora Forense, Rio de Janeiro, 2002.

MÁRDERO ARELLANO, Miguel A. Critérios para a preservação digital da informação científica. 2008. 356 f. Tese (Doutorado em Ciência da Informação) - Universidade de Brasília, Departamento de Ciência da Informação e Documentação, Brasília, 2008. Disponível em: repositorio.unb.br/bitstream/10482/1518/1/2008_MiguelAngelMarderoArellano. pdf. Acesso em: 18 dez. 2017.

MÁRDERO ARELLANO, Miguel A. Cariniana: uma rede nacional de preservação digital. Ciência da Informação, v. 41, n. 1, 2012. Disponível em: http://www.brapci.inf.br/index.php/res/v/21617. Acesso em: 18 dez. 2017.

MOREIRA, Leonardo Neves. Uma visão arquivística do sistema de Processo Judicial Eletrônico do Conselho Nacional de Justiça. Cadernos de Informação Jurídica, Brasília, v. 2, n. 2, p. 37-69, jul./dez. 2015. Disponível em: http://www.cajur.com.br. Acesso em: 09 out. 2017.

PARÁ. Tribunal de Justiça. Portaria Conjunta $n^{\circ}$ 001/2018- GP/VP. Dispõe sobre a tramitação do processo judicial eletrônico, no âmbito do Poder Judiciário do Estado do Pará. Diário da Justiça, Belém, n. 6434, p. 7-27. 29 maio 2018. Disponível em: https://dje.tjpa.jus.br/ClientDJEletronico/app/ home.html. Acesso em: 10 jun. 2018.

PARÁ. Tribunal de Justiça. Portaria $n^{\circ}$ 2766/2014-GP. Disciplina a utilização do Sistema Integrado de Gestão Administrativa - SigaDOC, destinado a produção, registro, comunicação, tramitação, de documentos, expedientes e processos administrativos em meio digital. Diário da Justiça, Belém, n. 5569, p. 8-33. 21 ago. 2014. Disponível em: https://dje.tjpa.jus.br/ ClientDJEletronico/app/home.html. Acesso em: 18 maio 2017.

RONDINELLI, Rosely Curi. $\mathbf{O}$ Conceito de documento arquivístico frente à realidade digital: uma revisitação necessária. 2011. 270 f. Tese (Doutorado em Ciência da Informação) - Universidade Federal Fluminense, Programa de Pós-Graduação em Ciência da Informação, Instituto de Arte e Comunicação Social, Instituto Brasileiro em Ciência e Tecnologia, Niterói, 2011. Disponível em: http://www.siarq.unicamp.br/siarq/images/siarq/publicacoes/preservacao_ digital/tese_rondinelli.pdf. Acesso em: 09 out. 2017. 
SILVA JUNIOR, Laerte Pereira da; MOTA, Valéria Gameleira da. Políticas de preservação digital no Brasil: características e implementações. Ciência da Informação, Brasília, v. 41, n. 1, p.51-64, jan./jun. 2012. Semestral. Disponível em: http://revista.ibict.br/cienciadainformacao/index.php/ciinf/ article/view/2123. Acesso em: 09 out. 2017.

UNESCO. Vancouver declaration: the memory of the world in the digital age: digitization and preservation. Disponivel em: http://www.unesco.org/file admin/MULTIMEDIA/HQ/Cl/Cl/pdf/mow/unesco_ubc_vancouver_declaration _en.pdf. Acesso em: 09 out. 2017.

Recebido em: 16/04/2018

Aceito em: 29/05/2019 